\title{
VISCOUS FLOW AND SURFACE FILMS ${ }^{1}$
}

\author{
By Ronald Bulkley
}

\section{ABSTRACT}

This paper describes experiments which have been made on the flow of various liquids through fine glass and platinum capillaries in an attempt to detect any departure from the laws of simple viscous flow. Such a departure could conceivably be brought about by an adsorbed layer on the walls of the capillary or by the attraction of the surface molecules of the walls upon the inclosed liquids. Flow-pressure graphs for various liquids in platinum and in glass capillaries have been obtained. The finest of these capillaries were, respectively, 9.35 and $5.59 \mu$ inside radius. The results are in agreement with the laws of simple viscous flow for all of the liquids investigated. Calculations of the radii of the tubes show that the thickness of any immobile adsorbed layer on the walls was not in excess of two to three hundredths of a micron. The diameters of the smallest glass capillaries were measured microscopically and were found to agree satisfactorily with the calculated values.

\section{CONTENTS}

I. Introduction

II. Discussion of previous work

III. The clogging of coarse capillaries...

IV. Flow tests of liquids in fine capillaries
1. Description of instrument and manner of operation

2. Purification of liquids

3. The viscosity equation; corrections to be applied.

4. Experimental results and their interpretation.

(a) Tests in capillaries $\mathrm{A}, \mathrm{B}$, and $\mathrm{C}$, glass

(b) Tests in capillary $\mathrm{D}$, platinum...

(c) Tests in capillary $\mathrm{E}$, platinum

(d) Final tests in platinum, capillary $\mathrm{F}$

(e) Final tests in glass, capillaries $\mathrm{G}$ and $\mathrm{H}$

V. Summary and acknowledgements

\section{INTRODUCTION}

The distance to which a solid surface is capable of altering appreciably the viscosity of a contiguous liquid is not well known. The practical importance of the problem arises largely from the desire of lubrication engineers to possess more knowledge as to the mechanism of lubrication by very thin films. It is generally accepted that the molecules in the first molecular layer of liquid in contact with the solid are fixed upon the surface molecules of the latter. The feeling of many investigators is that the influence of the solid extends very little further, if any further, than through this first layer of liquid molecules. Other experimenters have observed, however, that liquids have sometimes appeared to possess an abnormally high viscosity when in close proximity to a solid surface. This has led them to the

1 The substance of this paper was presented as a dissertation to the Johns Hopkins University in partial fulfillment of the requirements for the degree of doctor of philosophy, June, 1930. 
belief that orientation and adsorption of liquid molecules may take place in successive layers, and that this effect may continue until a film of relatively great thickness has been built up.

The rate of flow of a liquid through a capillary tube under constant pressure difference is known to vary directly as the fourth power of the diameter of the tube. It should, therefore, not be an insuperable task to detect any. considerable effect of the walls upon the viscosity of the contained liquid. If, for example, the effect were sufficient to prevent flow in a layer only a single micron thick adjacent to the walls, then in a tube $0.2 \mathrm{~mm}$ inside diameter the observed rate of flow would be 4 per cent lower than the theoretical value. The experiments to be described in the following paper were made in an attempt to detect the influence of the walls of fine glass and platinum capillaries upon the measured viscosity of various liquids which were passed through them.

\section{DISCUSSION OF PREVIOUS WORK}

Sir William B. Hardy is probably foremost among investigators who favor the view that a solid surface is capable of increasing the viscosity of a contiguous liquid to a relatively great distance. Hardy has done valuable pioneer work in helping to elucidate the perplexing phenomena of boundary lubrication. His conclusions as to the effect of a solid surface upon the viscosity of a neighboring liquid, however, appear to be inferential rather than based on direct experimental determinations of the viscosity. Thus in one instance, ${ }^{2}$ while using $p$-cymene as an adhesive, he found that a series of adhesion measurements between glass and steel gave results which were too low as compared with the results of certain other measurements considered normal. This led him to assume that the layer of $p$-cymene, which was 4 microns in thickness, had been changed by the fields of force of the inclosing solids from a "light spirit" to a "jelly." The molecules of the liquid were supposed to have been oriented and "locked in place by the attraction fields of the solids," the viscosity increasing to at least 200 times its normal value as a result. As. expressed in his latest paper, ${ }^{3}$ Hardy's final view is to the effect that none of the liquid between two solid surfaces is "free" unless the surfaces are separated by a distance greater than $10 \mu$. No additional experimental data to substantiate this view are given.

Many other investigators have put forth evidence to show that the viscosity of liquids, particularly of lubricating oils, is influenced to a considerable distance by a solid surface. Thus Gilson, ${ }^{4}$ Becker, ${ }^{5}$ and others have reported that the composition of the metals in a journal bearing influences the coefficient of friction in the régime of complete film lubrication when the shaft and journal are separated by a relatively thick film of lubricant. This is not in accord with the accepted theory of lubrication, ${ }^{6}$ and it could be brought about only by a specific effect of the metals on the viscosity of the liquid film. It is difficult to reconcile the conclusions of these investigators with the

W. B. Mardy and Millicent Nottage, Studies in 1 dhesion, Proc. Roy. Soc. A, 112, pp. 62-75; 1926.

The Analysis of Commercial Lubricating Oils by Physical Methods, Lubrication Research Tech. Paper No. 1 Dept. Sci. and Indust. Res., London, 66 pp.; 1930.

H. (ł. Gilson, Lubrication Round-Table Discussion, Ind. Eng. Chem., 20, pp. 847-848; 1928.

A. F. Becker, Surface Action and Fluid Film Lubrication, Ind. Eng. Chcm., 18, pp. 471-477; 1926.

- Mayo D. Hersey, Fundamental Action of Lubricants, Am. Machinist, 70, pp. 919-921; 1929. 
work of Kingsbury, ${ }^{7}$ who experimented at high rates of shear with "a slightly tapered plug rotating in a ring, the parts being of hardened steel, closely fitted by grinding. With films as thin as 0.000025 inch $(0.6 \mu)$ and rates of shear up to 261,000 radians per second, at atmospheric pressure and temperature, there was no indication of slip, and no deviation from the oridnary law of viscosity that could not be attributed to inaccuracy of the fitted surfaces."

Perhaps the most remarkable results to be found in the literature are those on the clogging of capillaries reported by Wilson and Barnard. ${ }^{8}$ These authors found that when oil containing a small amount of fatty acid or other polar material was allowed to flow through capillaries as large as $0.3 \mathrm{~mm}$ inside diameter, the capillaries gradually clogged and in many instances were closed up completely in a few hours. The mechanism of clogging is pictured as the progressive formation of an immobile layer on the inside of the capillary due to orientation and selective adsorption of the polar components. These results have met with wide acceptance among scientific and technical workers in many countries. They constitute in large measure the foundation for a theory which Karplus ${ }^{9}$ has formulated to embrace both the régimes of boundary and complete film lubrication. They are quoted in the masterly treatise of Woog,,$^{10}$ although Woog discovered that the clogging he observed in some similar experiments of his own was due to the lodging of foreign threadlike filaments in the capillary. Vieweg and Kluge ${ }^{11}$ consider the work of Wilson and Barnard to be of such fundamental importance that they have recently republished several of the original diagrams to show the clogging of capillaries with prolonged flow of liquid. Dover ${ }^{12}$ repeated the clogging experiments taking great care to reproduce Wilson and Barnard's conditions as closely as possible. She found that the capillaries became clogged, but she obtained "very erratic results." Ormand, ${ }^{13}$ Ries, ${ }^{14}$ Johansen, ${ }^{15}$ and others also indorse the Wilson and Barnard theory of thick-film adsorption.

\section{THE CLOGGING OF COARSE CAPILLARIES}

In view of the wide acceptance given the above-mentioned experiments on the clogging of capillaries, it was deemed advisable to repeat them before attempting the more difficult task of measuring the flow of liquids through finer capillaries than have been used for this purpose heretofore. At first a viscometer was employed which was purposely of an entirely different design from that of Wilson and Barnard to avoid any inherent faults that may have been present in their apparatus or method. The instrument was so constructed as to bring the different variables under direct control. For example,

7 Albert Kingsbury, Report of Subcommittee on Lubrication, Mech. Eng. 41, p. 537; 1919.

8 R. E. Wilson and D. P. Barnard, Fourth, Measurement of the Property of Oiliness, J. Ind. Eng. Chem., 14, pp. 683-694; 1922 .

25, pp. 375-386; 1929.

${ }_{10}$ Paul Woog, Contribution à L'Étude du Graissage, Delagrave, Paris, 1926.

11 V. Vieweg and J. Kluge, Ueber Messungen der Schmierfahigkeit von Oelen in Lagern, Archiv. f. das Eisenhlittenwesen, 2, pp. 1-7, 1929

12 M. V. Dover, Lubricating Efficiencies of Oils, Ind. Eng. Chem., 18, p. 499; 1928.

18 W. R. Ormandy, Lubrication, Proc. Inst. Mech. Eng., 1, pp. 291-329; 1927 .

14 E. D. Ries, Relation between Physical Characteristics and Lubricating Values of Petroleum Oils, Ind. Eng. Chem. Analytical Ed., 1, p. 187; 1929 .

${ }_{13}$ E. M. Johansen, Interfacial Tension between Petroleum Products and Water, Ind. Eng. Chem., 16, pp. 132-135; 1924. 
the pressure producing the flow could be varied at will, a constant temperature bath was employed and only a single capillary was investigated at a time. Four capillaries in all were investigated; one of glass, $0.20 \mathrm{~mm}$ inside diameter; one of nickeline, $0.25 \mathrm{~mm}$ inside diameter; one of platinum, $0.25 \mathrm{~mm}$ inside diameter; one of steel, $0.35 \mathrm{~mm}$ inside diameter.

Clogging was experienced from the start. In Figure 1 are shown graphs for three typical runs using essentially the same method of plotting as employed by Wilson and Barnard. However, since the pressure producing flow was not constant but was purposely varied

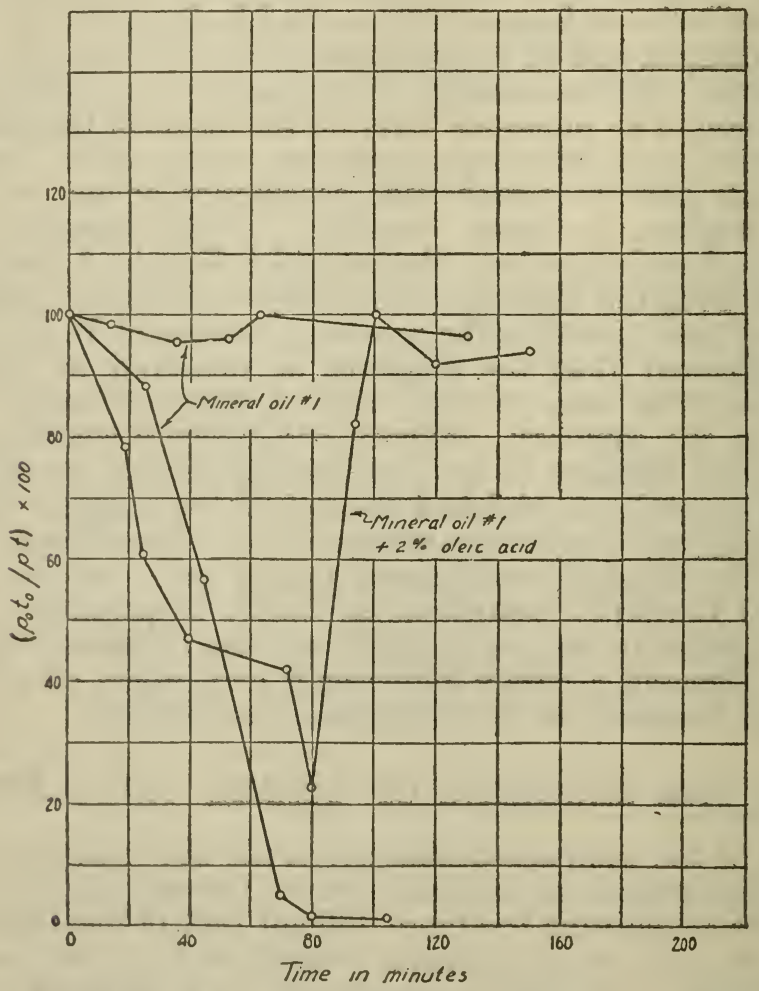

FiguRE 1.-Flow of inadequately filtered oils through coarse nickeline capillary

from time to time to test the proportionality of rate to pressure difference, it is the $p t$ value instead of the rate of discharge which should here remain constant for a nonclogging oil, ${ }^{10}$ that is, the ratio $p_{0} t_{0} / p t$ should always be unity for nonclogging oils, $p_{o}$ being the initial pressure producing flow, $t_{o}$ the initial time for unit discharge, and $p$ and $t$ the corresponding values at any subsequent time.

As in the tests of Dover, the most characteristic feature of these graphs is their erratic appearance. Wilson and Barnard and Dover used only a 200-mesh sieve (see fig. 2) for filtering the oils they tested. In the present investigation all liquids, whether for test or for rinsing

16 Emil Hatschek, The Viscosity of Liquids, D. Van Nostrand Co., 1928. 
the apparatus, were filtered through an asbestos or paper filter, but still without consistent results. To prevent contamination from the atmosphere and to minimize the number of fibers which might be detached from the under side of the filter, a pellet of loosely packed clean cotton wool was placed directly over the entrance to the capillary where it was allowed to remain during test, no other filtering of the liquid being employed. The rate of flow was then found to be not only steady with time at a given pressure difference, but also directly proportional to the pressure producing the flow. Repeated tests with various oils and capillaries served only to confirm the evidence that a filtering device as simple as a cotton pellet was sufficient in all cases to give consistent and reproducible results with capillaries as large as those listed above.

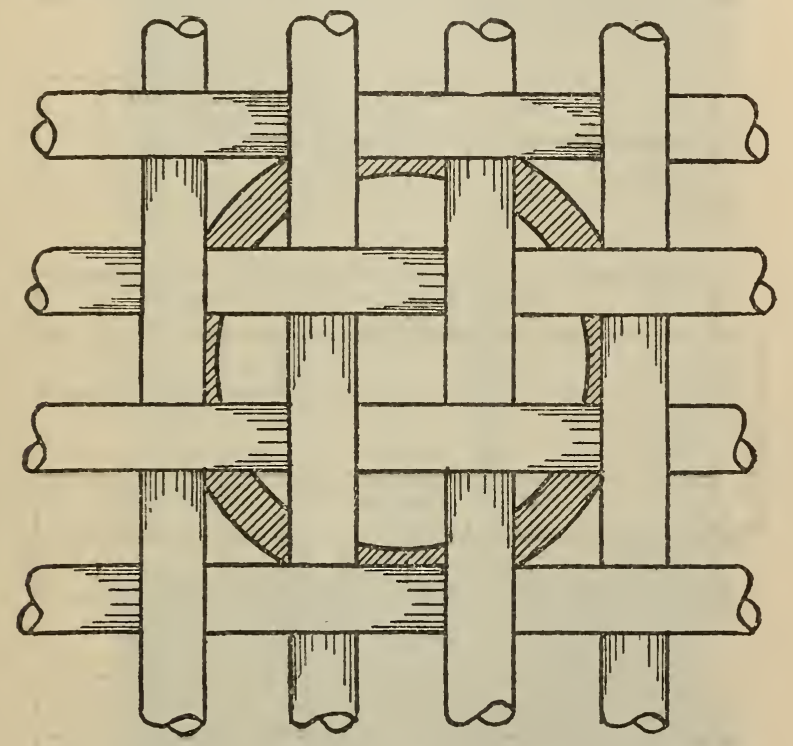

FIgURE 2.-Magnified skeich of capillary $0.3 \mathrm{~mm}$ nside diameter beneath 200-mesh sieve

In all, 18 complete tests were made before adopting the expedient of filtering inside the instrument. These embraced tests made in all four capillaries with several different kinds of oil, both fatty and mineral. In 12 of these tests clogging took place to the extent of retarding the rate of flow 20 per cent or more. After adopting the cotton-wool method of filtering, 10 runs were made using the same oils and capillaries. None of the 10 showed clogging sufficient to slow down the rate of flow by as much as 10 per cent, and only 1 run showed a decrease in the rate greater that 5 per cent. Figure 3 shows typical graphs for test data on three of the capillaries using the improved method of filtering. On the thick adsorbed-film theory all the oils used here should clog the capillaries rapidly.

The four capillaries were next mounted in an apparatus exactly similar to that of Wilson and Barnard as shown in Figure 4. Figure 5 shows curves for typical runs made on an oil containing 1.2 per cent stearic acid using Wilson and Barnard's method of test. Figure 6 
shows tests on the same oil under identical circumstances except that a loose layer of cotton was used to cover the capillaries. These tests were made without temperature control, and the variations in rate for the tests of Figure 6 are well within the errors to be expected. To demonstrate that the cotton had no other effect than to filter out foreign particles, a great mass of it was saturated with oil and allowed to stand for 24 hours. Enough oil for test was then gently expressed and tested by Wilson and Barnard's method. Clogging was as pronounced as in any previous test, but when the capillaries were cleaned
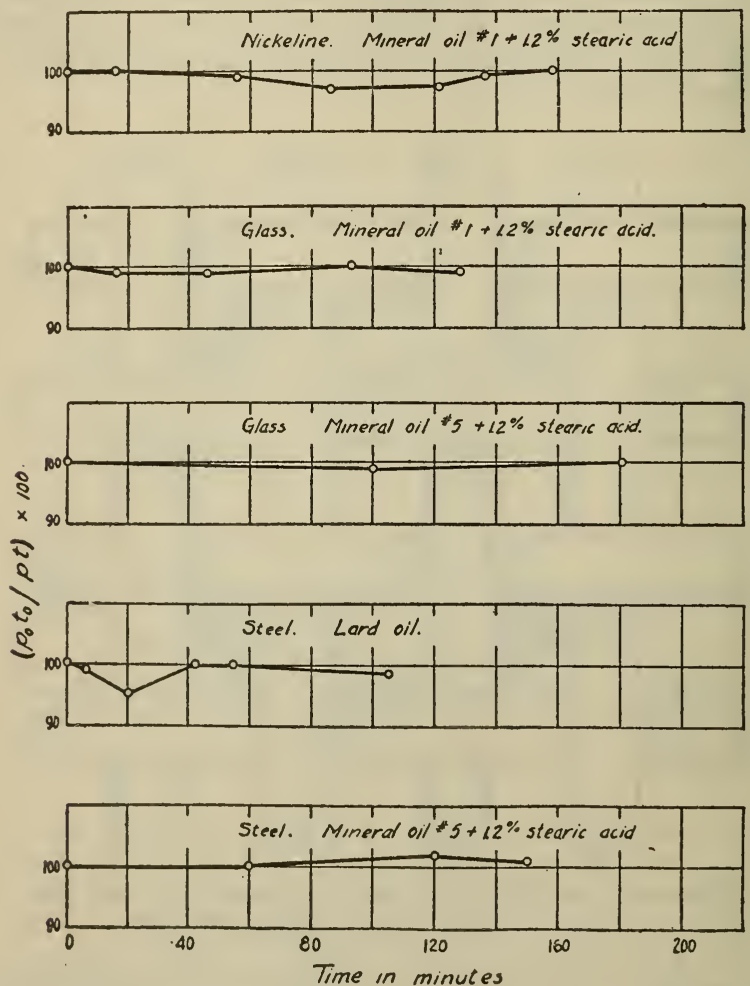

FigdRE 3.-Flow of oils through coarse capillaries, improved filtering

and covered loosely with some of the same cotton the rate of flow was steady at its initial value for several hours. The results obtained up to this point seem to show conclusively that the clogging of capillaries observed by Wilson and Barnard could be attributed mainly, if not entirely, to foreign matter in the oils they used.

\section{FLOW TESTS OF LIQUIDS IN FINE CAPILLARIES}

\section{DESCRIPTION OF INSTRUMENT AND MANNER OF OPERATION}

It is obvious that tests must be performed under better experimental conditions than those just described, and that more searching criteria must be applied to the tests if it is desired to gain a quantita- 


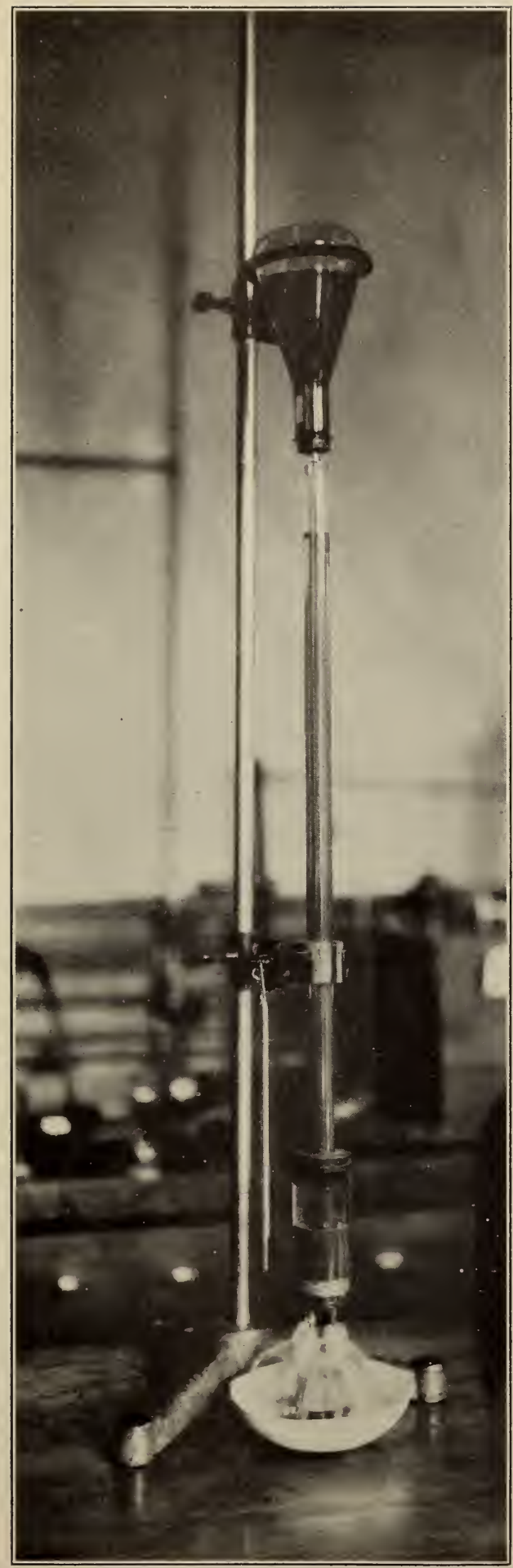

Figure 4.-Apparatus similar to that of Wilson and Barnard 

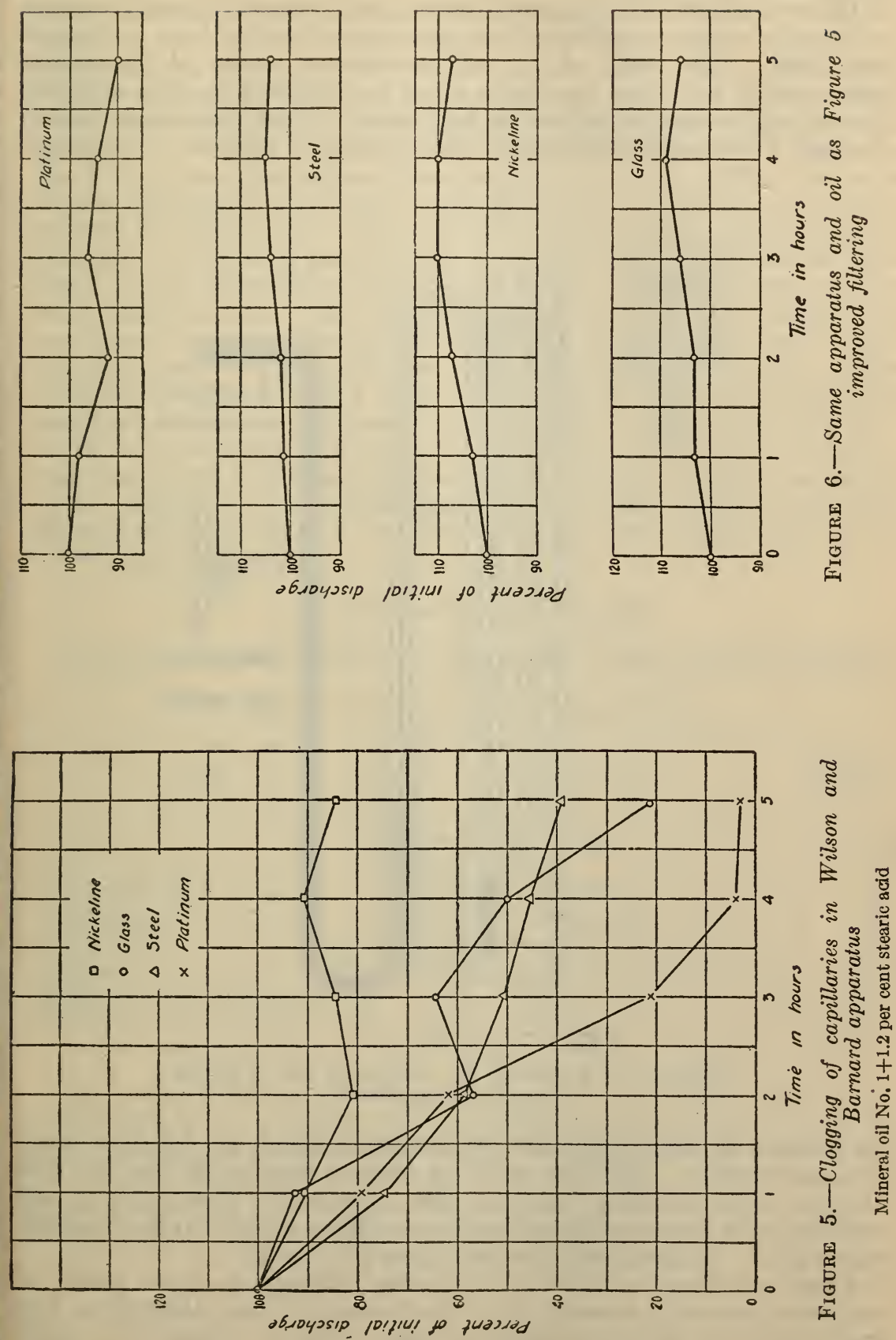

$26284^{\circ}-30-7$ 
tive idea as to the thickness of the stagnant layer adjacent to the walls of the capillary.

Figure 7 shows the apparatus developed to meet the requirements which had been emphasized as important by the tests in coarse capillaries. The body of the viscometer was made of small-bore glass tubing bent into the shape of an $\mathrm{S}$. One of the open ends was tapered and arranged to be sealed off at will with a lead cap as shown. $A$ short $T$ was sealed into the middle member of the $S$ in such manner

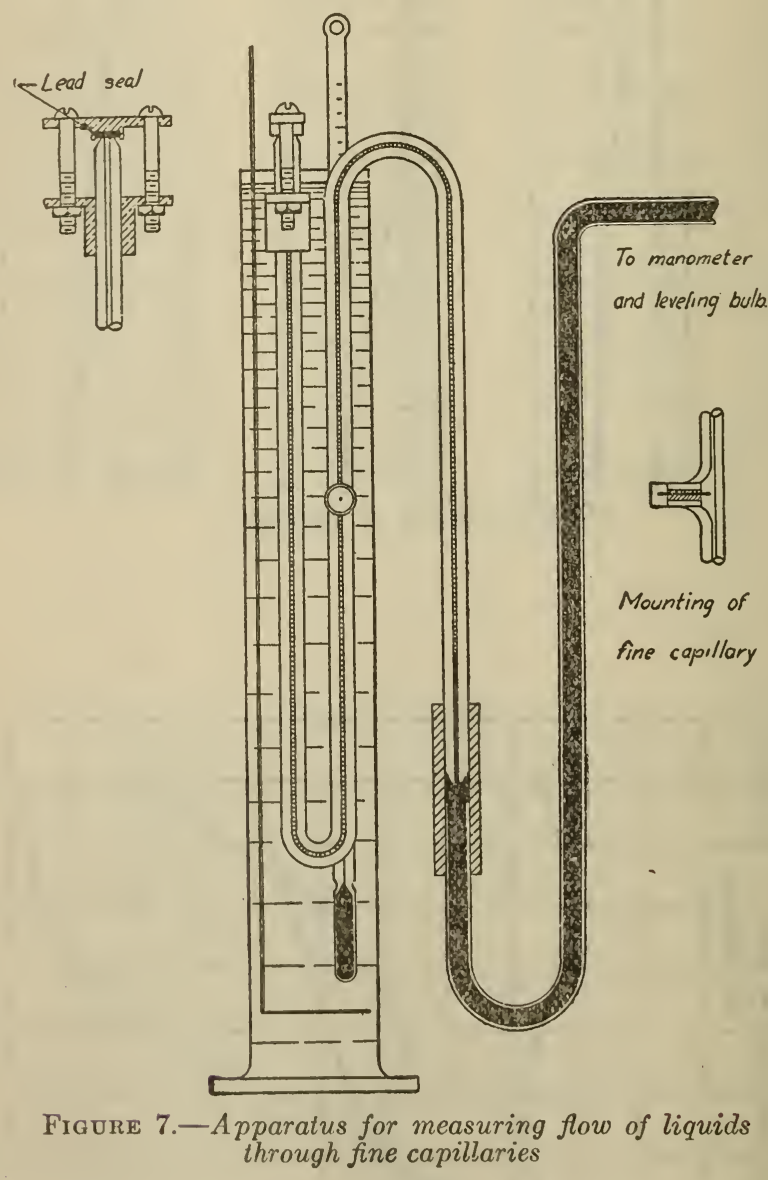

as to leave no narrow pockets or crevices in which air bubbles could become trapped. The fine capillary for test was sealed into this side tube by a low-melting cement. The manometer was simply a tall vertical tube mounted close beside a millimeter scale and connected directly to a leveling bulb through pressure tubing.

Dust-free liquid obtained by filtering through a dense grade of unglazed porcelain directly into the viscometer was allowed to run freely through the instrument for some time to cleanse the walls thoroughly of any loose particles of dust. Then, with the instrument completely full of test liquid, the cap was screwed into place and the 
viscometer was connected with the pressure system in such manner as to place the test liquid in direct contact with the mercury. To avoid an interfacial tension correction at the discharge end of the capillary the latter was immersed in a small auxiliary thermostat filled with a liquid miscible with the one under test. This small thermostat, along with the viscometer, was placed in a larger bath not shown in Figure 7, which maintained the temperature constant at $30^{\circ} \mathrm{C}$. within $0.01^{\circ} \mathrm{C}$. To obtain the uncorrected pressure producing flow the vertical distance between the mercury meniscus in the viscometer and that in the manometer tube was read to the nearest half millimeter. The rate of flow was obtained by measuring the rate of ascent of the mercury meniscus into the calibrated right limb of the viscometer, using a miscroscope cathetometer reading accurately to $5 \mu$. With few exceptions the error in reading the position of the mercury menisci was not in excess of 1 per cent of the net pressure. No rates of flow were calculated from a time of less than 40 seconds or from a total vertical rise of the mercury meniscus less than $0.5 \mathrm{~mm}$. Accurate determinations of the rate of flow were made for each liquid at four or more pressures covering as wide a range as could be managed conveniently. When tests on one liquid were complete a second dust-free liquid miscible with the first was allowed to wash out the first one, and the cycle of operations given above was repeated.

\section{PURIFICATION OF LIQUIDS}

The essential information for the liquids used is given in Table 1.

TABLE 1.-Liquids used in viscosity tests

\begin{tabular}{|c|c|c|}
\hline Liquid & Criterion of purity & $\begin{array}{l}\text { Viscosity, } \\
30^{\circ} \mathrm{C} \text {. poises }\end{array}$ \\
\hline $\begin{array}{l}\text { Benzene } \\
\text { Do } \\
\text { Conductivity water } \\
\text { White mineral oil } \\
\text { Oleic acid } \\
n \text {-caprylic acid } \\
n \text {-butyl alcohol } \\
\text { Ethyl alcohol } \\
\text { p-cymene } \\
\text { Kerosene } \\
\text { White oil plus } 1 \text { per cent oleic acid } \\
\text { White oil plus } 1 \text { per cent } m \text {-cresol. }\end{array}$ & $\begin{array}{l}\text { Timmermans'; M. P. } 5.493^{\circ} \mathrm{C} \\
\text { Baker's C. P } \\
\text { Superpure, p }=6.7 \text {. } \\
\text { Special treatment with sodium } \\
\text { Eastman's. } \\
\text { Eastman's; M. P. } 14^{\circ} \text { to } 15^{\circ} \mathrm{C}^{\circ} \\
\text { Eastman's; B. P. } 116^{\circ} \text { to } 118^{\circ} \mathrm{C} \\
\text { Absolute grade... } \\
\text { Eastman's; terpene-freo, B. P. } 176.5^{\circ} \text { to } 177.5^{\circ} \mathrm{C} \\
\end{array}$ & $\begin{array}{l}0.00574 \\
.00575 \\
.00801 \\
.151 \\
.256 \\
.0463 \\
.0230 \\
.0100 \\
.00752 \\
.0188 \\
.152 \\
.146\end{array}$ \\
\hline
\end{tabular}

No attempt was made to obtain the acids, the butyl alcohol, and the $p$-cymene in a higher state of chemical purity than that of the best commercial product obtainable. Putting aside the very great difficulty ${ }^{17}$ of purifying some of these materials, there would still seem to be little purpose in using them in the purest state, since the polar compounds are preferentially adsorbed on a solid surface from a mixture containing both polar and nonpolar bodies. This preferential action is so marked that as little as 2 per cent of stearic acid in a mineral oil may be as effective in reducing friction as the pure acid. Moreover, the impurities present in compounds of this type

17 Arthur Lapworth, Leonore K. Pearson, and Edward N. Mottram, The Preparation and Properties of Purified Oleic Acid, Biochem. J., 19, pp. 7-18; 1925. 
are usually other polar compounds which are not likely to diminish the thickness of the adsorbed layer or lessen in any other way the change in viscosity which may take place due to contact with a solid surface.

This same phenomenon, the preferential adsorption of the polar bodies, imposes the requirement that the nonpolar liquids shall be scrupulously pure and free from polar material. The ultimate standard or reference liquid which was chosen to fulfill this condition was pure benzene. As auxiliary reference liquids not likely to contain molecules with a "loaded end," conductivity water and a specially prepared white mineral oil were used. The pure benzene was obtained from the laboratory of Prof. J. Timmermans, of the University of Brussels. This benzene is recommended by the International Bureau of Physical Chemical Standards as possessing the highest possible purity obtainable. ${ }^{18}$ The conductivity water was prepared in the laboratory of Dr. S. F. Acree, of the National Bureau of Standards, in the special stills developed largely under his direction.

This water was free from sprayed-over impurities and from carbon dioxide. It gave a $\mathrm{pH}$ of 6.7 when tested with a brom-thymol blue indicator adjusted to give the same $\mathrm{pH} .{ }^{19}$ The specially prepared mineral oil was selected as answering, about as well as anything to be had, the need for a pure nonpolar compound or mixture of compounds in the paraffin series. The white oils as purchased are generally recognized as being free from polar compounds. However, in order to be reassured on this point the oil was allowed to stand for several days over a large amount of freshly cut sodium. It was agitated frequently during this period and the presumption is that any bodies likely to be selectively adsorbed by platinum or glass were similarly adsorbed by the much more active sodium and removed. The oil was then filtered and washed with warm distilled water until, when a sample of it was shaken with phenolphthalein, neither the oil nor the water layer showed any color after standing several hours. It was then dried for some days over C. P. calcium chloride, filtered and carefully stoppered.

The porcelain filters which were used to remove dust from the liquids were, when new, invariably found to impart an alkaline reaction to water filtered through them. They were accordingly boiled for some time in dilute acetic acid and then rinsed repeatedly in distilled water until a sample of conductivity water gave the same $\mathrm{pH}$ after filtering as before, namely, 6.7. The filters were then thoroughly dried and stored in a clean cabinet until needed.

With the exception of the value for conductivity water the viscosities quoted in Table 1 were determined in the viscometry laboratory of the National Bureau of Standards by F. G. Bitner. A Bingham viscometer was used which had been calibrated with distilled water, taking as the viscosity of the latter the value recommended by Professor Bingham ${ }^{20}$ and used at the National Bureau of Standards. The value quoted by Professor Timmermans, for the viscosity of his benzene is 1.4 per cent lower than the value given in Table 1. Tim-

19 J. Timmermans and F. Martin, Etude de Vingt Hydrocarbures et Dérivés Halogénés, J. Chim. Phys., 23, pp. 747-787; 1926. See also same volume, pp. 733-746.

10 S. F. Acree and Edna H. Fawcett, The Problem of Dilutior in Colorimetric H-Ion Measurements, J. Bact., 17, pp. 163-204, 1929. Also see Fawcett and Acree under the same title in Ind. Eng. Chem., Analy. Ed., 2, pp. 78-85; 1930 .

${ }^{20}$ Eugene C. Bingham and Richard F. Jackson, Standard Substances for the Calibration of Viscometers, B. S. Sci. Paper No. 208. B. S. Bulletin, 14, pp. 59-86; 1918-19. 
mermans and Martin used an Ostwald viscometer which also had been calibrated with water, but they chose for the viscosity of the latter the mean of the values given in Landolt-Börnstein. No details of the viscosity determinations are given and it is believed that the values given in Table 1 are more reliable than that determined by Timmermans and Martin.

\section{THE VISCOSITY EQUATION; CORRECTIONS TO BE APPLIED}

Bingham, ${ }^{21}$ Hatschek, ${ }^{22}$ and others have treated the theory of viscous flow of a liquid through a capillary tube so thoroughly that no discussion of the general principles involved need be given here. The complete equation may be written

where

$$
\eta=\frac{\pi P R^{4} t}{8(L+\lambda) Q}-\frac{m Q d}{8 \pi(L \cdot+\lambda) t}
$$

$\eta=$ viscosity of liquid in poises.

$P=$ pressure producing the flow in dynes $/ \mathrm{cm}^{2}$

$R=$ radius of capillary in centimeters.

$L=$ length of capillary in centimeters.

$Q=$ volume of liquid in $\mathrm{cm}^{3}$ discharged in $t$ seconds.

$d=$ density of liquid in $\mathrm{g} / \mathrm{cm}^{3}$.

and

$m=$ coefficient of kinetic energy correction.

$\lambda=$ Couette or end correction.

The correct values to be used for $m$ and $\lambda$ have been the subject of ninch controversy. This does not concern us here, however, since both $\lambda$ and the last term of equation (1) are negligible for the conditions which prevailed in the present investigation. The extreme values quoted in the literature for $\lambda$ are of the order of 1 or 2 diameters, with a strong probability that it is less than a single diameter. In the present investigation this correction was largest in the case of capillary D, of platinum, with a length of $1.35 \mathrm{~cm}$ and a diameter of approximately $0.0027 \mathrm{~cm}$. The correction was, therefore, less than 0.5 per cent, which is less than the error from other sources. The last term of equation (1) had its maximum value for the tests on water in the capillary just described. Accepting the value of 1.12 usually given for $m$, the last term was in the worst case only a hundredth of 1 per cent as large as the preceding term. Equation (1) then reduces at once to the form

$$
\eta=\frac{\pi P R^{4} t}{8 L Q}
$$

which is Poisuelle's law. For our present purpose it will be more convenient to write this equation in the form

$$
R^{4}=\frac{8 L \eta q}{\pi P}
$$

where $q=Q / t$, the rate of discharge in $\mathrm{cm}^{3}$ per second.

21 E. C. Bingham, Fluidity and Plasticity, McGraw-Hill; 1922.

22 Emil Hatschek, The Viscosity of Liquids, D. Van Nostrand Co.; 1928. 
In practically all forms of effux viscometer the apparent volume of liquid which has passed in a given time must be multiplied by a drainage factor to correct for the liquid which adheres to the walls of the measuring bulb. In the tables and graphs to follow, the rate of flow, $q$, has been calculated on the assumption that the mercury as it rose in the measuring tube displaced all the test liquid and filled the tube completely. As seen through the microscope, this condition seemed to be realized, but it is obvious that such could not actually have been the case. Hickman, ${ }^{23}$ however, has shown that a mercury drop placed on an oily surface soon squeezes out all the oil beneath it except a layer approaching molecular dimensions in thickness. The following test was made to determine the approximate thickness of the layer which adhered to the measuring tube of the viscometer after the mercury had displaced the oil.

A thin-walled glass tube was cleaned, dried, and accurately weighed. It was connected to the pressure system of the viscosity apparatus in place of the viscometer and was held in a vertical position. It was filled with oleic acid, and the leveling bulb was slowly raised to make the mercury pass upward into the tube at about the same vertical rate as was used, on the average, in the viscosity tests on oleic acid. The acid was thus displaced by mercury under conditions closely similar to those prevailing in the actual test. When the tube was completely filled with mercury it was dismounted, emptied of mercury, and wiped clean on the outside. It was weighed again, the difference between weighings representing the amount of oleic acid adhering to the inside walls. When the volume of this acid was divided by the total inside area of the tube the thickness of the layer was given as $11 \times 10^{-5} \mathrm{~cm}$. Assuming the same thickness of layer to adhere to the walls of the viscometer the volume of acid not displaced by the mercury in a test would be less than 1 per cent of the nominal volume of flow. It would be still less than this for the other liquids used. The correction was, therefore, considered negligible.

A correction of more importance is that which must be applied to the observed pressure to account for the capillary depression of the mercury meniscus in the measuring tube of the viscometer. This correction is hereafter called $c$, and it was determined separately for each liquid in the following manner: A U-tube was made in which one leg had closely the same inside diameter as the manometer and the other the same inside diameter as the measuring tube of the viscometer. The piece was mounted upright open to the atmosphere at both ends, mercury and test liquid being in contact in the small leg and clean mercury alone standing in the large leg. A little more mercury was then poured into the large leg to make the level in both sides rise. The vertical distance between the two mercury levels was then accurately measured with a cathetometer. This was repeated several times, the average vertical distance between the mercury surfaces for a given liquid being taken as the $c$ value. This value was found to be independent of the rate of rise of the mercury levels from zero rate up to the maximum used in tests, which was less than a centimeter a minute.

The head of mercury effective in producing flow is here called $p$ and is equal to $(m-h-c)$ where $m$ is the vertical distance between the

${ }^{21}$ K. C. D. Hickman, The Mercury Meniscus, J. Opt. Soc. Am. and Rev. Sci. Inst. 19, pp. 190-212, 1929. 
mercury level in the instrument and that in the manometer tube and $h$ is the correction for the head of liquid in the thermostat against which the test liquid discharged. The value of $h$ was always something less than a centimeter of mercury and changed somewhat during the tests on a given liquid as the mercury rose in the measuring tube. The value of $P$ in equations (1), (2), and (3) is the driving pressure in dynes per $\mathrm{cm}^{2}$. It was obtained by multiplying $p$ by the density of mercury at the average temperature of the room, taken as $25^{\circ} \mathrm{C}$., and by the acceleration of gravity. The change in $p$ during a test was small, and the difference between its effective value and the mean of its final and initial values has been disregarded. The final form of equation used in calculating the effective radius, with all the numerical values inserted which do not depend on either the liquid or the capillary, is

$$
R^{4}=\frac{8 L \eta}{3.1416 \times 981 \times 13.53}(q / p)
$$

In the diagrams which follow $q$ in $\mathrm{cm}^{3}$ isec. has been plotted against $p$ in $\mathrm{cm}$ of mercury, retaining the latter as a pressure unit in order to avoid unnecessary multiplications. It may be well to note that the ratio $q / p$ is merely the slope of the flow-pressure graph.

\section{EXPERIMENTAL RESULTS AND THEIR INTERPRETATION}

(a) TESTS IN GLASS CAPILLARIES A, B, AND C

Tests in these capillaries were performed while experimenting with various methods for obtaining dust-free liquids and while developing the technique of test. The results will not be discussed in detail, but one or two items of significance will be mentioned. It was discovered, for instance, that air must be rigorously excluded from the viscometer during test or a greatly exaggerated apparent rate of flow would be obtained, due to the solvent action of the test liquid on the contained air at pressures higher than atmospheric. Several methods of cleaning a fine glass capillary which had become clogged were tried, but none of them proved successful. Whenever a glass capillary clogged up, therefore, it was abandoned for another.

To determine how closely the flow through the capillaries conformed to the simple viscosity equation, the following criteria have been applied to the results of tests made in these capillaries, as well as to all that follow.

1. Is the radius of the capillary as calculated from equation (4) the same for different chemical compounds?

2 . Is the rate of flow steady with time for constant pressure difference?

3 . Is the rate proportional to the pressure producing the flow? The significance of these criteria will be discussed more fully after the experimental results for capillary $\mathrm{D}$ have been given.

When applied to the tests in capillaries A, B, and C, these criteria gave no indication of an adsorbed layer of appreciable thickness for any of the liquids tested. In some instances the liquid ran continuously through the capillary for four hours without any evidence of clogging. The points on the flow-pressure graphs were somewhat scattered in the earlier tests, but there was no systematic departure 
from linearity. Moreover, in these tests, as in all that follow, the results were independent of the order in which the points were taken. In some instances the first datum point was taken at the lowest pressure used for that graph, the next point at the highest pressure and the others at intermediate pressures. Other sequences were used for other liquids.

Two liquids were tested in capillary A: (1) A mineral oil plus 2 per cent oleic acid, and (2) U. S. P. oleic acid. The calculated values of the radius differed by $0.2 \mu$. Conductivity water and butyl alcohol were tested in capillary $B$, the viscometer receiving a quick rinse with filtered ethyl alcohol in between. The calculated values of the radius differed by $0.4 \mu$. In capillary $\mathrm{C}$ white mineral oil, oleic acid, benzene, and butyl alcohol were tested in the order named, with a maximum deviation of $0.26 \mu$ from the average calculated radius.

\section{(b) TESTS IN CAPILLARY D, PLATINUM}

Platinum was found to possess the advantage over glass that a given capillary, after clogging, could be removed from the instrument, cleaned by flaming just to redness, and used again. On the other hand, the platinum tubes were no doubt rougher on the inside than the glass capillaries. In general, clogging was found to be more frequent with platinum than with glass. This was attributed to roughness, the belief being that such filaments as did get into the viscometer found anchorage more readily along the serrated walls of the platinum tube than along the molecularly smooth walls of the glass ones.

The liquids listed in Table 2 were tested in capillary D. Although the capillary had not clogged, it was removed and gently flamed between the two check runs with white mineral oil. It clogged when the first attempt was made to test butyl alcohol, and it was, therefore, flamed before the test on this liquid which is reported in the table. It was flamed a third time before the test on conductivity water. The flow-pressure graphs are shown in Figure 8.

\section{TABLE 2.-Summary of tests in capillary $D$}

[Length, $1.350 \mathrm{~cm}$ ]

\begin{tabular}{|c|c|c|}
\hline Test liquid & $\begin{array}{l}\text { Approximate } \\
\text { total duration } \\
\text { of test }\end{array}$ & $\begin{array}{l}\text { Calculated } \\
\text { radius }\end{array}$ \\
\hline $\begin{array}{l}\text { White mineral oil } \\
\text { Do } \\
\text { Kerosene } \\
\text { Oleic acid } \\
\text { Butyl alcohol } \\
\text { Conductivity water. }\end{array}$ & $\begin{array}{r}\text { Minutes } \\
60 \\
60 \\
50 \\
120 \\
40 \\
30\end{array}$ & $\begin{array}{r}\mu \\
13.53 \\
113.53 \\
13.60 \\
13.60 \\
13.53 \\
13.60\end{array}$ \\
\hline
\end{tabular}

1 A single graph was used to average both sets of data for this oil.

A verage calculated radius, $13.57 \mu$.

Maximum deviation, $0.04 \mu$.

The significance of the three criteria given above may be considered to advantage at this point. The fundamental assumption underlying the derivation of equation (1) is that the linear velocity of the liquid passing through a small tube is zero only at the mathemetical wall 
of the capillary. The velocity of a layer any distance, $r$, from the axis of the tube is given by the expression,

$$
v=\frac{P}{4 L \eta}\left(R^{2}-r^{2}\right)
$$

which is the equation of a parabola, and shows the manner of variation of the linear velocity of the liquid along the radius of the tube. If, due to adsorption, the laminae at a finite distance from the walls

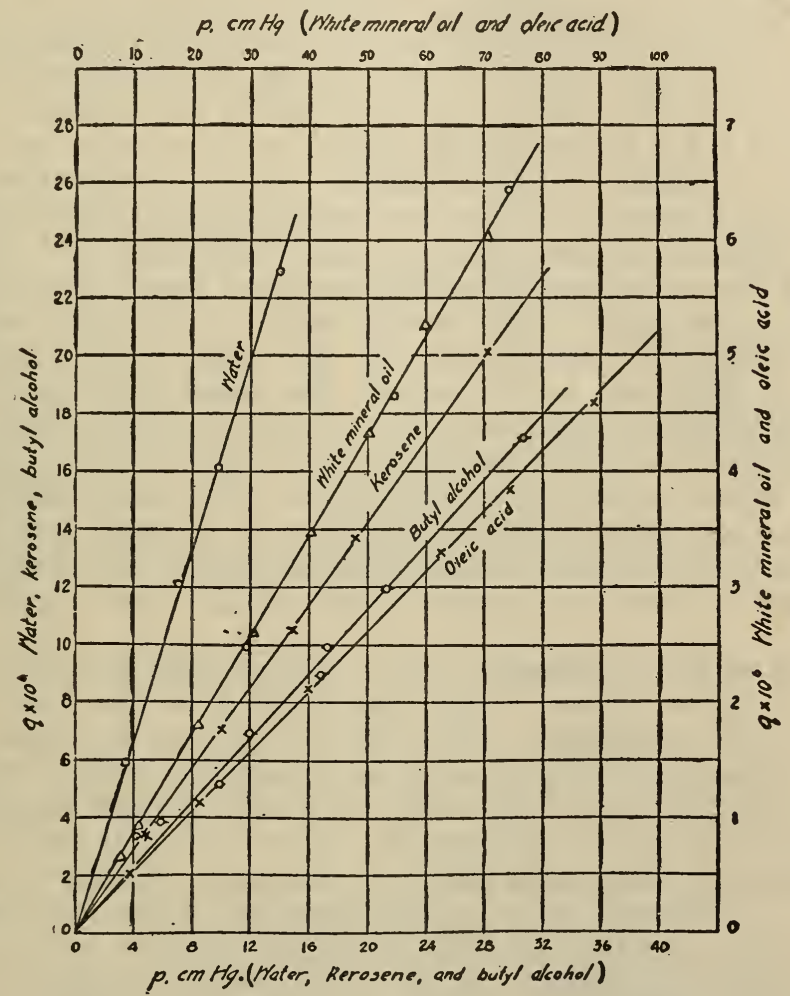

FigdRE 8.-Flow-pressure graphs for dust-free liquids in capillary $D$, platinum

are held immobile or are retarded in such manner as to produce a distortion of the normal parabolic are, this retardation or distortion will constitute a virtual reduction of the radius. Since the rate of flow is proportional to the fourth power of the radius a small reduction will be reflected in a relatively large decrease in the rate of flow. If a direct measurement of the diameter is possible, we are able at once to evaluate the magnitude of the reduction for any given liquid by comparing the measured diameter with the effective diameter as calculated from flow data by the viscosity equation. This requires, of course, that the viscosity of the liquid shall have been previously determined in a tube so large as to leave no question but that the reduction or constriction of the diameter due to adsorption was negligible. 
If, as in the present case, the diameter of the capillary can not be readily determined by direct measurement we may still hope to obtain valuable information by making appropriate tests and calculations. We can, for instance, calculate the effective radius for each of several liquids of different chemical compositions and compare the different values so found. If the adsorbed layer differs appreciably in thickness for different liquids we should by this means be able to arrange the liquids in the order of increasing thickness of adsorbed layer and estimate, at least roughly, how the thickness varies with the chemical composition. The differences between the calculated values for the radius may then, if desired, be looked upon as the difference which may possibly exist between the thicknesses of the adsorbed layer for the various liquids. What the absolute thickness of this layer is for any particular liquid, we have no means of determining for a capillary whose diameter can not be meaured directly. It is striking, however, that the amount of variation in the calculated values of $R$ has decreased almost to the vanishing point as the technique and the experimental conditions have been improved, and it seems only reasonable to believe that under ideal experimental conditions the calculated values would be the same for all liquids. This would very likely not be the case if the adsorbed film on the walls were of appreciable depth, as it is too much to expect that liquids as widely different as water and oleic acid, for instance, should have adsorbed layers of the same thickness. The most rational interpretation of the observations is, therefore, to assume that the law of simple viscous flow holds rigorously in all cases, and that the whole discrepancy between the various values of $R$ is due to experimental error.

The test of the constancy of rate of flow with time was the only one of the three criteria which was applied to the flow of liquids through coarse capillaries. Although no building up of an adsorbed layer could there be detected when the liquids were adequately filtered it is not inconceivable that some such effect could manifest itself in capillaries as fine as capillary D. The "latent period of orientation" of polar compounds, which is discussed at length by Hardy, should be manifested by a partial clogging of fine capillaries very similar to that observed by Wilson and Barnard for larger ones. As already indicated, clogging was actually observed in some of the tests attempted in capillary $\mathrm{D}$, but this was always of such a nature as to leave no room for doubt that it was produced by foreign particles. Progressive decrease in the $p t$ value was always accompanied by the same erratic behavior as characterized the clogging of coarse capillaries. For such tests the flow-pressure graphs were not linear and the calculated radii for all the points on the graph were less than for liquids which did not clog. When clogging was experienced in a first test of any particular liquid, a second attempt under more rigorous experimental conditions almost invariably proved successful in giving a run free from clogging. The middle column of Table 2 shows, for the various materials, the approximate period during which the liquids were actually flowing through the capillary. Over this period the $p t$ value was constant within the experimental error of the tests.

If there is a deep, stagnant layer next to the walls, its thickness, and, therefore, also the effective radius of the capillary, are very probably functions of the rate of flow and hence of the pressure dif- 
ference producing flow. Very close to the walls the film must be held entirely rigid and immobile, but at a little distance away we can suppose it to be less stable, due to the decreasing strength of the fields of force. Those portions of the film at some distance from the walls should then be swept along by high velocities of flow, but it is possible that they would reform and remain immobile when the velocity is decreased. We might reasonably expect to find, therefore, that the rate of flow is not a linear function of pressure unless the film is of an entirely insensible thickness. The flow-pressure graphs of Figure 8 pass through the origin and leave little to be desired in the way of linearity.

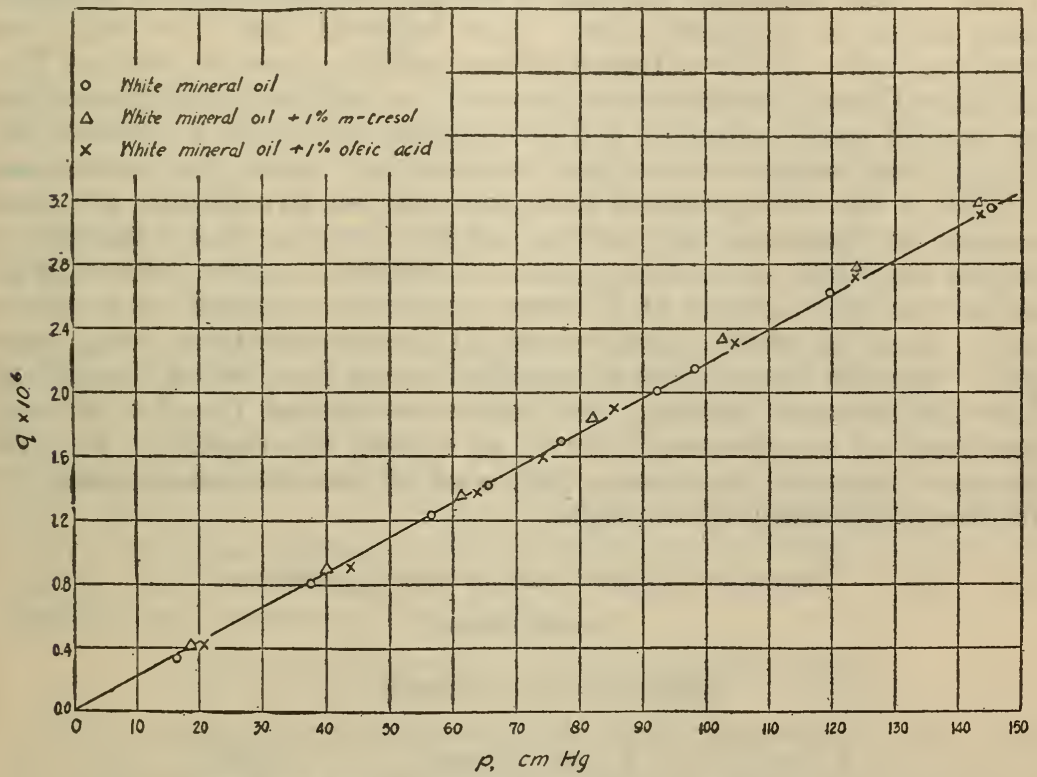

Figure 9.-Flow-pressure graphs for tests in capillary $E$, platinum

(c) TESTS IN CAPILLARY E, PLATINUM

Figure 9 shows that the same conclusions as drawn from the tests on pure or nearly pure liquids in capillary $\mathrm{D}$, apply equally well to tests on solutions of polar compounds in a nonpolar oil. Wilson found pronounced clogging of coarse capillaries with oils containing $p$-cresol. Merely because it was easily available, $m$-cresol was used here instead. The line in Figure 9 has been drawn to average the tests with white mineral oil; the graphs averaging the other two sets of points have been omitted to avoid confusion.

TABLE 3.-Summary of tests in capillary $E$

[Length, $1.480 \mathrm{~cm}$ ]

\begin{tabular}{|c|c|c|}
\hline Test liquid & $\begin{array}{l}\text { Approxi- } \\
\text { mate total } \\
\text { duration } \\
\text { of test }\end{array}$ & $\begin{array}{l}\text { Calculated } \\
\text { radius }\end{array}$ \\
\hline $\begin{array}{l}\text { White mineral oil } \\
\text { White mineral oil plus } 1 \text { per cent } m \text {-cresol } \\
\text { White mineral oil plus } 1 \text { per cent oleic acid. }\end{array}$ & $\begin{array}{r}\text { Minutes } \\
60 \\
60 \\
60\end{array}$ & $\begin{array}{ll}\mu & \\
9.85 \\
9.81 \\
9.86\end{array}$ \\
\hline
\end{tabular}


The liquids were tested in the order named in Table 3 and without removing the capillary for cleaning. To be assured that plenty of the essential "film forming constituents" remained in the filtered oil the acidity of the sample containing oleic acid was determined before and after filtering.

Per cent by weight

Oleic acid in unfiltered sample _...

Oleic acid in filtered sample

(d) FINAL TESTS IN PLATINUM, CAPILlaRY F

This capillary was prepared by Dr. L. Jordan, of the metallurgy division of the National Bureau of Standards, by drawing platinum tubing down in sapphire dies. It is believed that this tube was, therefore, more nearly cylindrical and uniform in cross section than capillaries $\mathrm{D}$ and $\mathrm{E}$ which were drawn in an ordinary steel draw plate. The liquids were tested in the order given in Table 5 without any clogging and without removing the capillary from the instrument. In Table 4 the flow-pressure data for tests on two liquids are given complete to illustrate the method of tabulation. For definition of symbols reference should be made to section 3 . The values of $q / p$ used in the calculations of $R^{4}$ were read from convenient points on graphs, each of which summarized all the observations for a given liquid. On the assumption of simple viscous flow for all liquids, the whole discrepancy between the values calculated for the radius is attributed to experimental error, as stated for capillary D. The difference between the various values of $R^{4}$ then becomes merely the criterion of accuracy of the tests.

TABLE 4.-Typical data for tests in capillary $F$

[Length, $1.480 \mathrm{~cm}$ ]

\begin{tabular}{|c|c|c|c|c|c|}
\hline \multicolumn{6}{|c|}{ TIMMERMANS' BENZENE, $c=1.7$} \\
\hline$m$ & $h$ & $p$ & $Q \times 10^{4}$ & $t$ & $q \times 10^{8}$ \\
\hline $\begin{array}{l}16.60 \\
28.05 \\
40.40 \\
19.75 \\
31.40\end{array}$ & $\begin{array}{r}0.65 \\
.55 \\
.50 \\
.35 \\
.30\end{array}$ & $\begin{array}{l}14.3 \\
25.8 \\
38.2 \\
17.7 \\
29.4\end{array}$ & $\begin{array}{r}5.86 \\
15.4 \\
15.4 \\
8.40 \\
14.0\end{array}$ & $\begin{array}{r}93.0 \\
125.0 \\
87.2 \\
105.0 \\
101.2\end{array}$ & $\begin{array}{c}6.30 \\
12.3 \\
17.7 \\
8.00 \\
13.8\end{array}$ \\
\hline \multicolumn{6}{|c|}{$R^{4}=\frac{8 \times 148 \times 0.00574 \times 17 \times 10^{-6}}{3.1416 \times 981 \times 13.53 \times 36.7}=7,569 \times 10^{-10}$} \\
\hline \multicolumn{6}{|c|}{$R=9.325 \mu$} \\
\hline \multicolumn{6}{|c|}{$n=\mathrm{CAPRYLIC}$ ACID, $c=1.6$} \\
\hline $\begin{array}{l}54.60 \\
44.15 \\
33.65 \\
23.30 \\
13.05 \\
64.60\end{array}$ & $\begin{array}{r}0.60 \\
.55 \\
.55 \\
.50 \\
.45 \\
.40\end{array}$ & $\begin{array}{l}52.4 \\
42.0 \\
31.5 \\
21.2 \\
11.0 \\
62.6\end{array}$ & $\begin{array}{l}\text { 4. } 89 \\
\text { 3. } 90 \\
4.72 \\
\text { 3. } 73 \\
\text { 1. } 87 \\
\text { 3. } 79\end{array}$ & $\begin{array}{l}159.4 \\
162.8 \\
257.8 \\
298.0 \\
289.0 \\
107.6\end{array}$ & $\begin{array}{l}3.07 \\
2.39 \\
1.83 \\
1.25 \\
0.647 \\
3.52\end{array}$ \\
\hline & $R^{\prime}=$ & 10 & & $3 \mu$ & \\
\hline
\end{tabular}


TABLE 5.-Summary of tests in capillary $F$

\begin{tabular}{|c|c|c|c|}
\hline Test liquid & $\begin{array}{l}\text { Approxi- } \\
\text { mate dura- } \\
\text { tion }\end{array}$ & $\begin{array}{l}R_{\text {s }}^{\text {calcu- }} \\
\text { lated }\end{array}$ & $\begin{array}{l}R, \text { calcu- } \\
\text { lated }\end{array}$ \\
\hline $\begin{array}{l}\text { Timmermans' benzene } \\
\text { Baker's benzene } \\
\text { Oleic acid } \\
\text { n-caprylic acid-a } \\
\text { p-cymene } \\
\text { White mineral oil- }\end{array}$ & $\begin{array}{r}\text { Minutes } \\
20 \\
30 \\
60 \\
40 \\
30 \\
60\end{array}$ & $\begin{array}{r}\times 10^{10} \\
7,569 \\
7,586 \\
7,656 \\
7,586 \\
7,647 \\
7,735\end{array}$ & $\begin{aligned} & \mu \\
& 9,325 \\
& 9,333 \\
& 9.354 \\
& 9.333 \\
& 9.352 \\
& 9.318\end{aligned}$ \\
\hline
\end{tabular}

A verage $R^{4}$, calculated, 7,633×10-16; maximum deviation 1.4 per cent

A verage $R$, calculated, $9.349 \mu$; maximum deriation $0.029 \mu$.

The flow-pressure graphs are shown in Figure 10. Only two items call for special mention. The first is that the ordinary C. P. grade of benzene gave a graph almost identical with that resulting from the benzene purified so rigorously by Professor Timmermans. The second is the behavior of $p$-cymene. This liquid, according to Hardy's tests, has a zero latent period of orientation. Accordingly, if it behaves with regard to platinum as it does with regard to glass and steel, and if Hardy's inference as to the influence of these materials upon it is correct, it should, upon entering the capillary, instantly build up a jellylike layer on the inside walls to a thickness of at least $2 \mu$. The resulting value of $R^{4}$ should be in the neighborhood of $2,500 \times 10^{-16}$ instead of $7,600 \times 10^{-16}$. In other words, the apparent viscosity should be about three times as high as the true viscosity in bulk. The tests here reported show, however, that the liquid behaves in all respects as a normal viscous substance, and that it gives a calculated radius differing by only $0.003 \mu$ from the average radius obtained with the other five liquids.

\section{(e) FINAL TESTS IN GLASS CAPILLARIES G AND $\mathbf{H}$.}

These two capillaries were cut from adjacent positions in the middle of a tube which was nearly uniform in cross section and about 4 feet in length. They were, therefore, expected to be of essentially the same radius. Tables 6 and 7 show a summary of the tests, the data for which are plotted in Figures 11 and 12.

TABLE 6.-Summary of tests in capillary $G$

[Length, $1.270 \mathrm{~cm}$ ]

\begin{tabular}{|c|c|c|c|}
\hline Test liquid & $\begin{array}{l}\text { Approxi- } \\
\text { mate dura- } \\
\text { tion }\end{array}$ & $\begin{array}{l}R_{\text {S }}^{\text {calcu- }} \\
\text { lated }\end{array}$ & $\begin{array}{l}R, \text { calcu- } \\
\text { lated }\end{array}$ \\
\hline 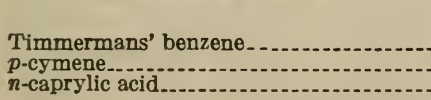 & $\begin{array}{r}\text { Minutes } \\
60 \\
60 \\
120\end{array}$ & $\begin{array}{r}\times 1010 \\
968.9 \\
966.5 \\
991.2\end{array}$ & $\begin{array}{r}\mu \\
5.579 \\
5.576 \\
5.611\end{array}$ \\
\hline
\end{tabular}



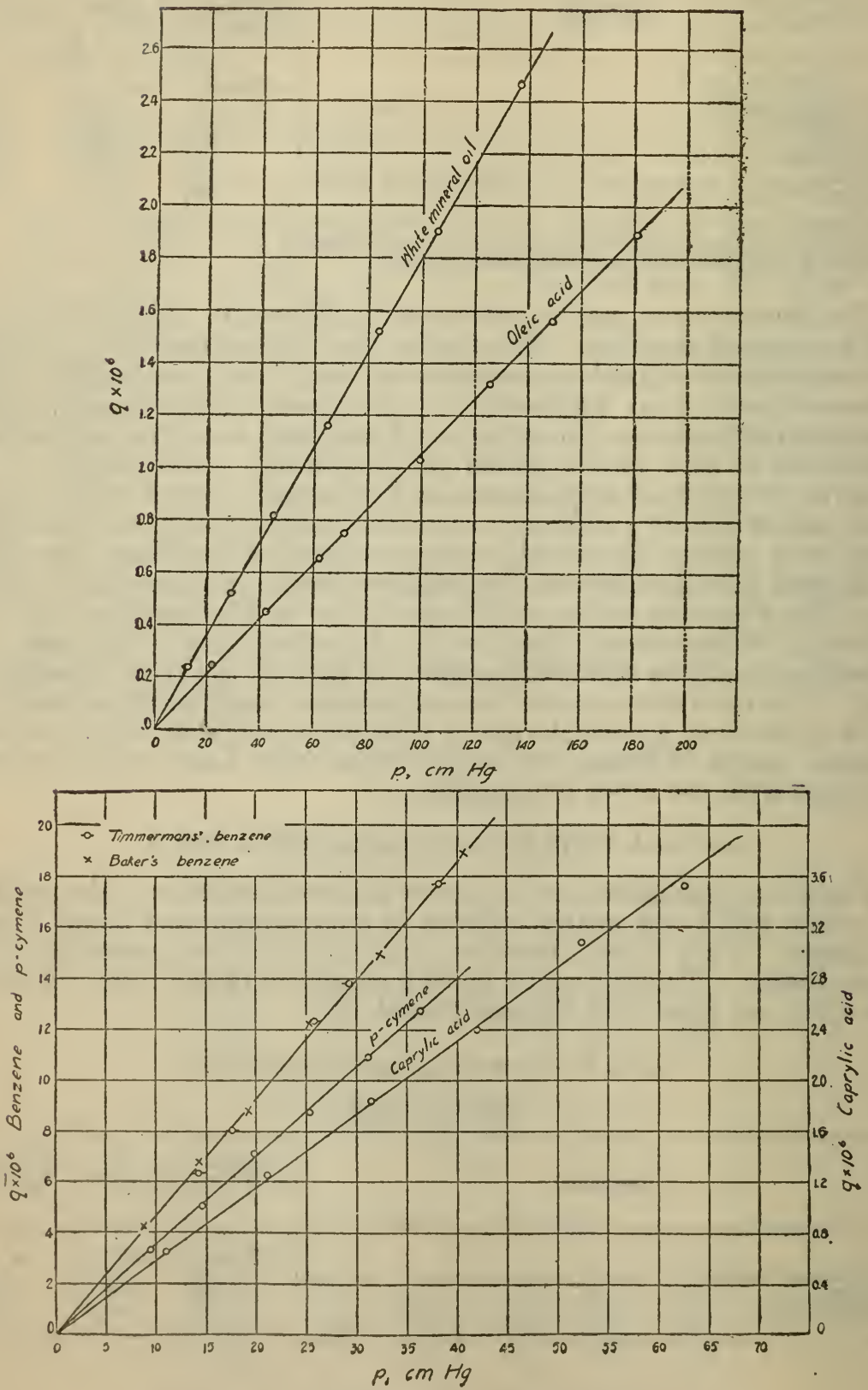

Figure 10.-Final tests in platinum, capillary $F$ 
TABLE 7.-Summary of tests in capillary $H$

[Length, $1.249 \mathrm{~cm}$ ]

\begin{tabular}{|r|r|r}
$\begin{array}{c}\text { Approxi- } \\
\text { mate durs- } \\
\text { tion }\end{array}$ & $\begin{array}{c}R^{4} \text { calcul- } \\
\text { lated }\end{array}$ & $\begin{array}{c}R \text {, calcu- } \\
\text { lated }\end{array}$ \\
\hline Minutes & $\times 10^{16}$ & $\mu$ \\
60 & 962.6 & \multicolumn{2}{c}{5.570} \\
60 & 981.0 & 5.596 \\
120 & 983.8 & 5.601 \\
\hline
\end{tabular}

Conductivity

$n$-caprylic acid

A verage $R^{4}$, calculated, capillaries $\mathrm{G}$ and $\mathrm{H}$, $975.8 \times 10^{-16}$.

Maximum deviation, 1.6 per cent.

A verage $R$, calculated, capillaries $\mathrm{G}$ and $\mathrm{H}, 5.589 \mu$.

Maximum deviation, $0.022 \mu$.

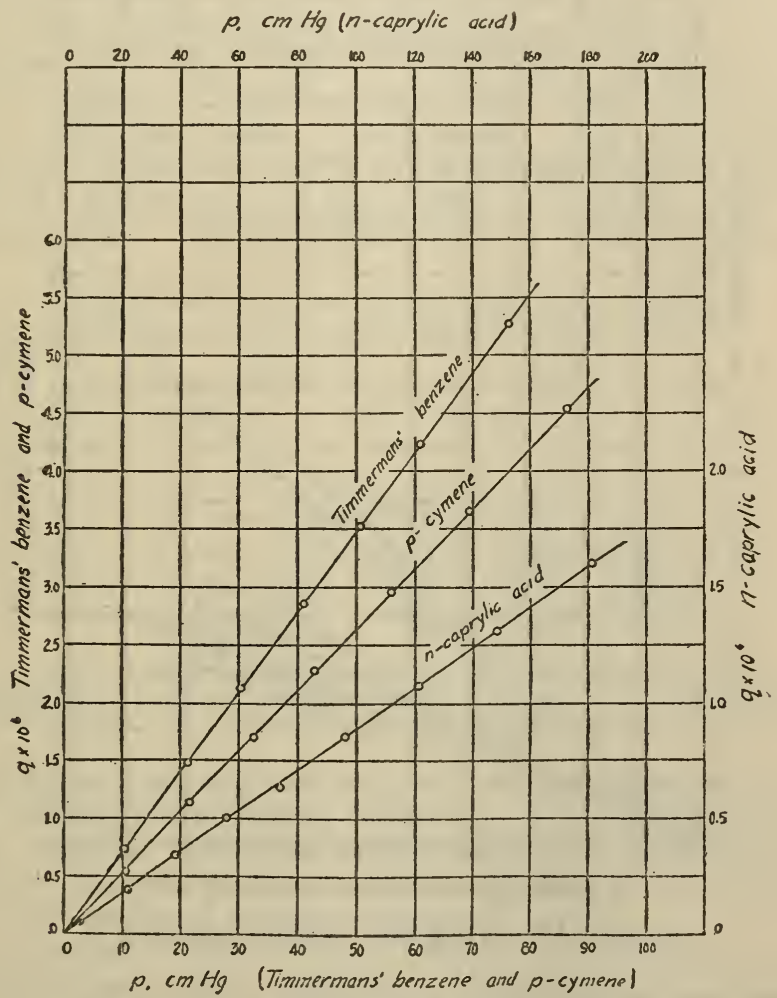

FigURE 11.-Final tests in glass, capillary $G$

Glass was one of the materials, which, in Hardy's experiments, appeared to exercise a profound influence on the viscosity of $p$-cymene to a distance of $2 \mu$. The tests here reported show no effect at distances of the order of $0.02 \mu$.

It is usually stated that the time required for the polar molecules to reach their maximum degree of orientation is greatly decreased by vigorous agitation or shear. For polar liquids passing rapidly through a capillary tube the conditions should then be particularly favorable for the prompt formation of the rigid oriented film on the walls. The tests her etofore discussed in this paper constitute strong evidence 
that no such rigid film exists of a greater thickness than $0.02 \mu$. There remains the possibility that an effect is present which is masked rather than accentuated by the shearing of the layers of liquid past each other through the capillary. This effect should manifest itself to best advantage in a test made at a low rate of shear after the liquid had been allowed to remain undistrubed for a long period of time so as to allow the walls of the capillary to produce maximum orientation upon the inclosed molecules.

The data for the last and lowest point shown on the graph for $n$-caprylic acid on Figure 11 were obtained under such circumstances,

$p, \mathrm{~cm} \mathrm{Hg}$ (n-caprylic acid)

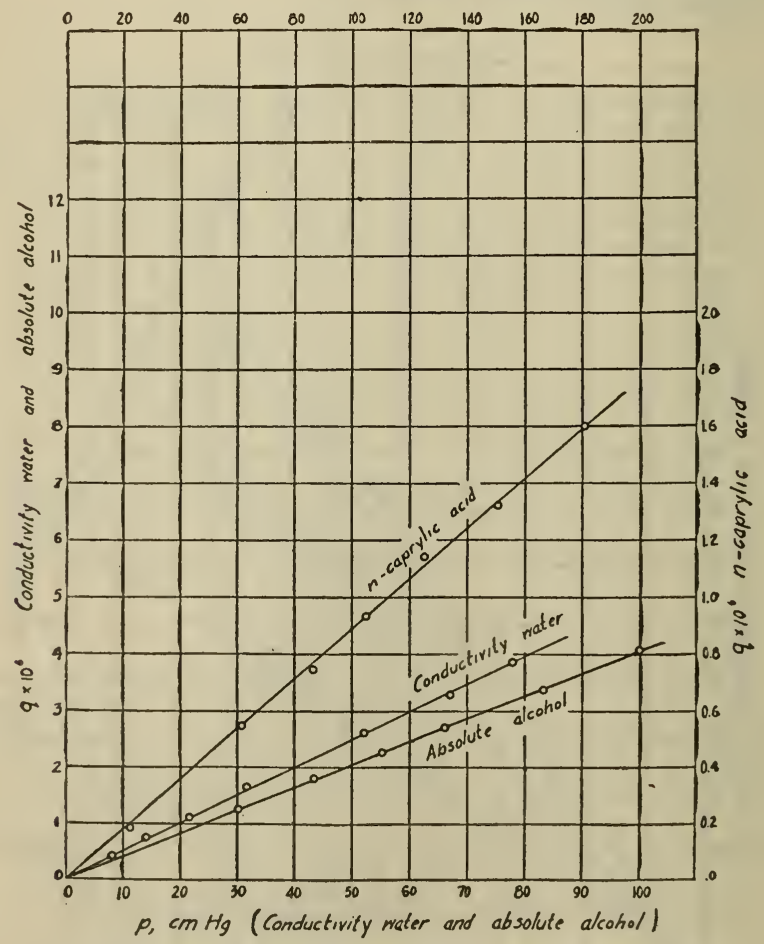

Figure 12.-Final tests in glass, capillary $H$

and do not possess the same percentage accuracy as those taken at higher pressures. After data for all the other points had been taken, the pressure was dropped to zero by lowering the leveling bulb almost to the zero point and opening the lead seal at the top of the viscometer. Since the top of the liquid in the thermostat was practically on the same level as the top of the viscometer there could be no flow through the fine capillary in either direction. The apparatus was left undisturbed in this condition for 16 hours, the fine capillary being full of test liquid during the entire period. The lead cap was then screwed tight, the cross hair of the cathetometer was adjusted to be tangent 10 the mercury meniscus in the measuring tube, and a low pressure was suddenly applied. A stop watch was started at the same instant. 
As far as the eye could judge by observing the meniscus through the microscope the liquid started flowing instantly. Since the rate of fluw was so low that more than 16 minutes were required for less than $4 / 100,000$ of a cubic centimeter of liquid to pass through the capillary, even a small abnormality in the viscosity should have been readily detected. As far as can be judged, however, the point representing this test falls accurately on the line averaging the other points. The shearing stress at the walls of the capillary was only 8.8 dynes per square centimeter for this test.

After the tests and calculations had been completed, capillaries $\mathrm{G}$ and $\mathrm{H}$ were submitted for measurement to Dr. L. V. Judson, chief of the length section of the National Bureau of Standards. His determinations of the diameters were made by the method of Shereshefsky, ${ }^{24}$ the capillaries being sealed over at the ends and immersed in a mixture of carbon disulphide and acetone of the same refractive index as the glass. The filar screw micrometer had been checked against a calibrated stage micrometer. Two diameters of each capillary were measured, but it is not known whether these were the major or the minor axes of the ellipse or whether they were some intermediate axes. The determinations are given complete in Table 8.

TABLE 8.-Diameters of glass capillaries (microns) ${ }^{1}$

\begin{tabular}{|r|c|c|c|}
\hline \multicolumn{2}{|c|}{ Capillary G } & \multicolumn{2}{c|}{ Capillary $\mathrm{H}$} \\
\cline { 1 - 4 } \multicolumn{1}{|c|}{$D_{1}$} & \multicolumn{1}{|c|}{$D_{2}$} & $D_{1}$ & $D_{2}$ \\
\hline 11.00 & 10.94 & 10.82 & 11.14 \\
10.98 & 10.80 & 10.68 & 11.02 \\
10.97 & 11.01 & 10.88 & 10.91 \\
10.03 & 11.09 & 10.65 & 11.08 \\
10.96 & 10.97 & 10.91 & 11.00 \\
\hline A verage 10.99 & 10.98 & 10.79 & 11.03 \\
\hline
\end{tabular}

1 The values given in this table differ slightly from the values given in the original dissertation due to a small correction which had not been applied when the original manuscript was written.

The arithmetic average of all microscopic measurements gives a value of $5.474 \mu$ for the radius, which is $0.115 \mu$ less than the average calculated radius. The maximum deviation on any single measured diameter is $0.18 \mu$, which is essentially as great as the difference between average calculated and average measured values.

The discrepancy between the measured and calculated values for the radius of these glass capillaries is equivalent to an error of about 9 per cent in the viscosity of a liquid, but it is in the wrong direction to be accounted for on the assumption either of an adsorbed layer on the walls or of an increase in viscosity due to the fields of force of the surface molecules of the capillary. It is in the right direction to be accounted for in part by the "drainage" error which was neglected. If any theoretical significance could be attached to it other than errors of measurement, it would be that there is slip of the liquid at the walls of the capillary. There is no occasion for admitting this hypothesis, however, since the discrepancy is no greater than might

24 J. L. Shereshefsky, A Study of Vapor Pressures in Small Capillaries, J. Am. Chem. Soc., 50, nD. 2966-2880; 1928.

$26284^{\circ}-30-8$ 
reasonably be expected from tests in and measurements of such small capillaries as here employed. There is a discrepancy of about 0.3 per cent between the values used by the National Bureau of Standards and those given by the International Critical Tables for the viscosity of such an all-important calibrating liquid as distilled water. The discrepancy of 1.4 per cent between the viscosity of benzene as found in this investigation and as quoted by the International Bureau of Physical Chemical Standards has already been referred to. Since these relatively great discrepancies exist for work done in ordinary viscometers in which it is possible to measure the diameters and the rates of flow very accurately, the error of 9 per cent is probably not excessive for the microviscometer used in this investigation. In any event the relative values for the radius of any given capillary as found by calculation for different liquids lose none of their significance from the discrepancy existing between measured and calculated radii. It can, therefore, be stated with some confidence, both for glass and platinum capillaries, that the thickness of any fixed layer adjacent to the walls is not in excess of two to three hundredths of a micron, or approximately a millionth of an inch.

\section{SUMMIARY AND ACKNOWLEDGMENTS}

- Measurements of the flow of various fatty and mineral oils through steel and nickeline capillary tubes as small as 0.18 and $0.13 \mathrm{~mm}$ inside radius, respectively, have shown that there is no clogging of the tubes, over long periods of time when the liquids are adequately filtered. Similar measurements have been made on a much greater variety of liquids using platinum and glass capillaries as small as $9.35 \mu$ and $5.59 \mu$ inside radius, respectively. By applying to these measurements certain criteria based on the laws of simple viscous flow it has been shown that these liquids retain their ordinary bulk viscosity at least as close to the solid surfaces as two to three hundredths of a micron, or about a millionth of an inch.

In conclusion, the author wishes to express his gratitude to Profs. J. C. W. Frazer and Walter A. Patrick, of the Johins Hopkins University, and to Mayo D. Hersey and Winslow H. Herschel, of the National Bureau of Standards, for their many helpful suggestions and criticisms. He is indebted to F. G. Bitner for the sketches, and to the others whose names are mentioned in the text for the assistance they have rendered. The cost of the investigation has been defrayed in part by the Special Research Committee on Lubrication, American Socicty of Mechanical Engineers.

Washington, October 18, 1930. 